\title{
THE SECRETS OF S. MARIA DELLE GRAZIE: VIRTUAL FRUITION OF AN ICONIC MILANESE ARCHITECTURE
}

\author{
C. Bolognesi ${ }^{1}$, D. Aiello ${ }^{2}$ \\ ${ }^{1}$ Politecnico di Milano, ABC department, 20131 Milan, Italy - cecilia.bolognesi@ polimi.it \\ ${ }^{2}$ Graduated from Catania University, 95123 Catania, Italy - damianoaiello@gmail.com
}

Commission II, WG II/8 KEY WORDS: Virtual Reality, Cultural Heritage, Serious Game, Digital Survey, 3D Modelling, Photogrammetry, Terrestrial Laser
Scanning

\begin{abstract}
:
The aim of this paper is to demonstrate the power of the new digitization technologies and, in particular, of Virtual Reality (VR) to document and communicate the knowledge of Cultural Heritage $(\mathrm{CH})$ and to shorten the distance between man and his history, enhancing architectural monuments or art masterpieces (even when they are somehow inaccessible), allowing original educational storytelling and producing innovative ways to learn and enjoy culture. The ultimate goal of this research is the virtual and interactive reconstruction of an important historical site, characterized by a great beauty as well as by a high artistic value: the complex of Santa Maria delle Grazie, in Milan. In order to test an effective digitization workflow, the experimentation focused on the areas of the convent that are closer to the church and that have been characterized by a troubled history: The Cloister of the Frogs, the Cloister of the Prior, the Old Sacristy, the Small Sacristy and the New Sacristy. These environments have been surveyed by combining photogrammetry and terrestrial laser scanning; then they have been modelled as NURBS or reconstructed in the form of meshes. In the end, the entire 3D model was imported in a game engine in order to create a realistic VR simulation, able to revive the convent's history in a way that no written document could better explain.
\end{abstract}

\section{INTRODUCTION}

In the last years, the digital survey and the 3D modelling techniques have been subjected to a significant development in all their fields of application: particularly, they have been oriented towards the digitization and creation of virtual environments, designed for educational purposes as well as for the dissemination of Cultural Heritage.

In this context, the outcomes of digital survey, such as point clouds or meshes (obtained from laser scanning or photogrammetric techniques), have been increasingly developing in terms of accuracy; they thus allow detailed 3D reconstructions of the most complex architectural masterpieces and give the opportunity to trace their features and their development over the centuries, in order to discover unknown aspects and new pages of their past.

This research deals with the creation (starting from a combined digital survey) of a VR interactive simulation that makes it possible to experience in an innovative way some important environments of S. Maria delle Grazie Convent (Milan).

The aim of the research group was to use this VR experience to deepen the knowledge and promote the visibility of this place, which is undoubtedly one of the most iconic ones in the historic centre of Milan, but which is also part, from a certain point of view, of the forgotten Cultural Heritage of the city. Very often, in fact, visitors do not deeply understand the beauty of this emblematic architecture, since it is famous all over the world only for Leonardo's Last Supper. This is one of the reasons why the distracted tourists usually ignore or underestimate the uniqueness of the entire complex: their interest is rarely attracted to the cloisters, the Sacristy of Bramante or the Small Sacristy, because in most cases they only look for a direct access to the Refectory (that hosts the Last Supper). The present experimentation can thus offer the possibility to reverse this trend, helping people to stimulate their curiosity and their emotional involvement even when they come into contact with the less known places of this ancient site.

\section{RELATED WORKS}

The experience of the digital survey aimed at the virtual reconstruction of Cultural Heritage has been extensively debated in the current literature. In this regard, it is possible to mention the well-known surveys of the Cathedral of Milan (Tommasi et al., 2016) and of Pietà Rondanini (Mandelli et al., 2017), that are two important references for deeply understanding the complexity of survey and the management of data in a web platform for maintenance.

Since the surveying techniques started offering the possibility to produce detailed results in terms of point clouds and (consequently) meshes, digital survey and 3D modelling are considered as the first natural step for designing virtual and augmented simulations, becoming an effective and powerful medium for $\mathrm{CH}$ dissemination: it is the case of the virtual reconstruction of the Roman theatre of Benevento (Campi et al., 2019) or of the reconstruction project of the Palazzo di Cosimo de' Medici, in the Fortezza Vecchia site (Livorno, Italy), heavily damaged by World War II bombings and subsequently razed (Bevilacqua et al., 2019).

Besides developing an important market in terms of new hardware and software (Gaitatzes et al., 2001), these simulations are able to allow the transmission (in user-friendly ways) of knowledge and content that have been, until today, the prerogative of specialists and experts.

Thanks to this extraordinary effectiveness in disseminating $\mathrm{CH}$ and in helping the diffusion of educational content, in the last years, the new digital technologies (above all Virtual and Augmented Reality) have started to develop engaging and innovative ways to collect, analyse and enhance the knowledge of $\mathrm{CH}$ sites. The majority of the projects developed in this context aim at digitally preserving $\mathrm{CH}$ for the next generations 
and at breaking down physical barriers, shortening the distances between man and $\mathrm{CH}$.

The opportunity offered by virtual reality to let users act firsthand in a 3D model and to experience inaccessible or destroyed places, opens a wide scenario in which different data and information can be offered to the public in the form of virtual museums or immersive simulations (Aiello et al., 2019; Banfi et al., 2019; Curiosity Stream, 2018; Dhanda et al., 2019).

The possibility of enriching the $\mathrm{CH}$ perception and deeply understanding it is also offered by AR. Unlike VR, it does not replace reality but empowers it by overlapping digital content such as texts, images or holograms on top of the user's environment in real time, changing the idea of fruition into an innovative, dynamic and engaging "experience".

In this context, it is possible to mention several Augmented Reality experiences (ArtGlass, 2017; Carrión-Ruiz et al., 2019; Liestøl, 2014; Palma et al., 2019; 7reasons Medien GmbH, 2018).

In many cases, $\mathrm{VR}$ and $\mathrm{AR}$ simulations are related to the paradigm of serious game: this concept refers to gaming experiences that allow new ways of learning, characterized by a playful component (Anderson et al., 2010; Candy et al. 2014; Liestol, 2014; Pietroni, 2013).

\section{CASE STUDY}

The Dominican convent of Santa Maria delle Grazie was established in the middle of 1400 on a pre-existing military camp, already provided of a chapel dedicated to the Virgin Mary. After 1466, this chapel was incorporated into the new church, designed and built by Guiniforte Solari (in the typical forms of transition between Gothic and Renaissance) and radically modified at the end of the 15 th century as strongly requested by Ludovico il Moro, who wanted to transform the temple into his family's mausoleum. In these years it is thought that Bramante was called to build the Tribune, the Cloister of the Frogs and the Old Sacristy. In the same period, Leonardo da Vinci took part in the completion of the convent's decorative apparatus: he painted the Last Supper in the Refectory (Martelli, 1981) and probably contributed to the vault decoration of the Bramante's Sacristy.

Over the years, other environments have been added to the complex, all around the original core constituted by the chapel of Santa Maria delle Grazie, that can be considered the real fulcrum of the convent (Fig. 1).

Instead of following the entire development of the complex through the centuries (topic already discussed in a previous research), in this paper the researchers pointed out some typical minor topics that still raise many interesting questions.

The first one regards the misalignment of the Chapel of Santa Maria delle Grazie with respect to the general layout of the church, as reported in the essays by Bruschi (AAVV, 11937); the access from the primitive chapel to the church is actually considered unusual, if related to the position of the transept and to the dictates of the classical tradition. Therefore, the chapel has been taken into consideration to explain many of the assumptions about the layout of the adjacent areas of the complex; in fact, as a consequence of the presence of the chapel since XV century, some empty spaces were generated between the chapel itself and the Bramante's Cloister of the Frogs. These spaces had to be filled with covered rooms. This is a possible explanation of the creation of the New Sacristy.

The latter was built in a first moment according to the length of the adjacent Cloister of Frogs, but it was partially demolished during the aerial bombardment of 1943. Only after the II World
War the sacristy was rebuilt and extended, preceding of a few years the reconstruction of the Cloister of the Prior.

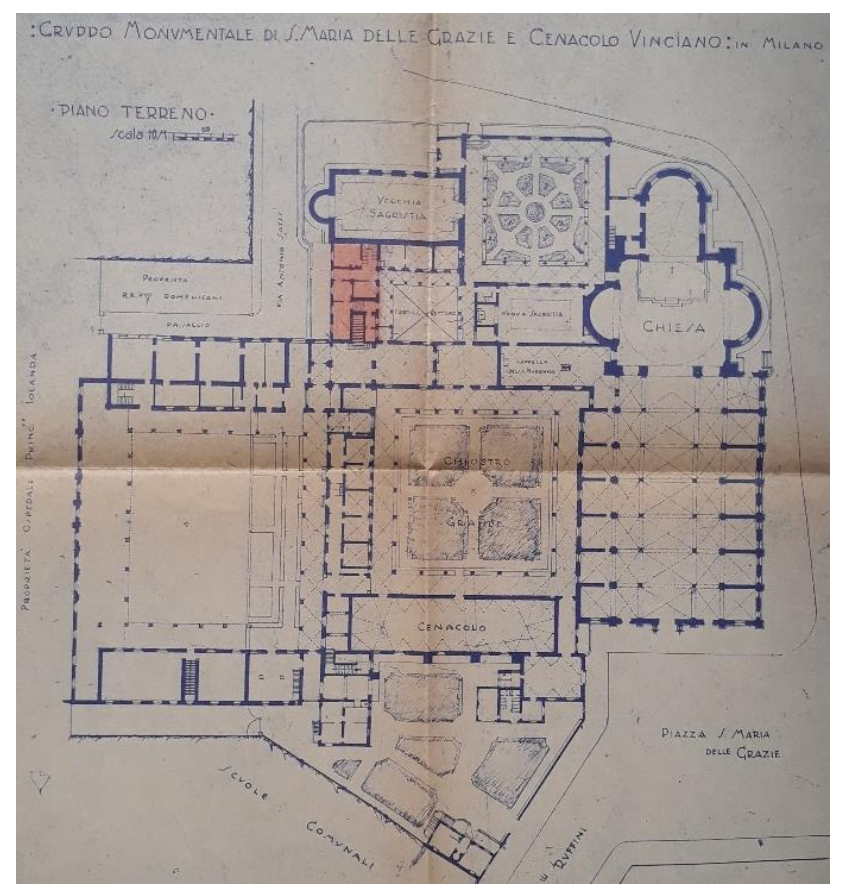

Figure 1. Plan of the convent before the II World War.

This cloister, more than any other parts of the convent, was object of non-accidental demolitions (Fig. 2) and reconstructions in the attempt to use via Sassi as privileged monumental access to the church, facing the Bramante's tribune (AAVV, 2003).

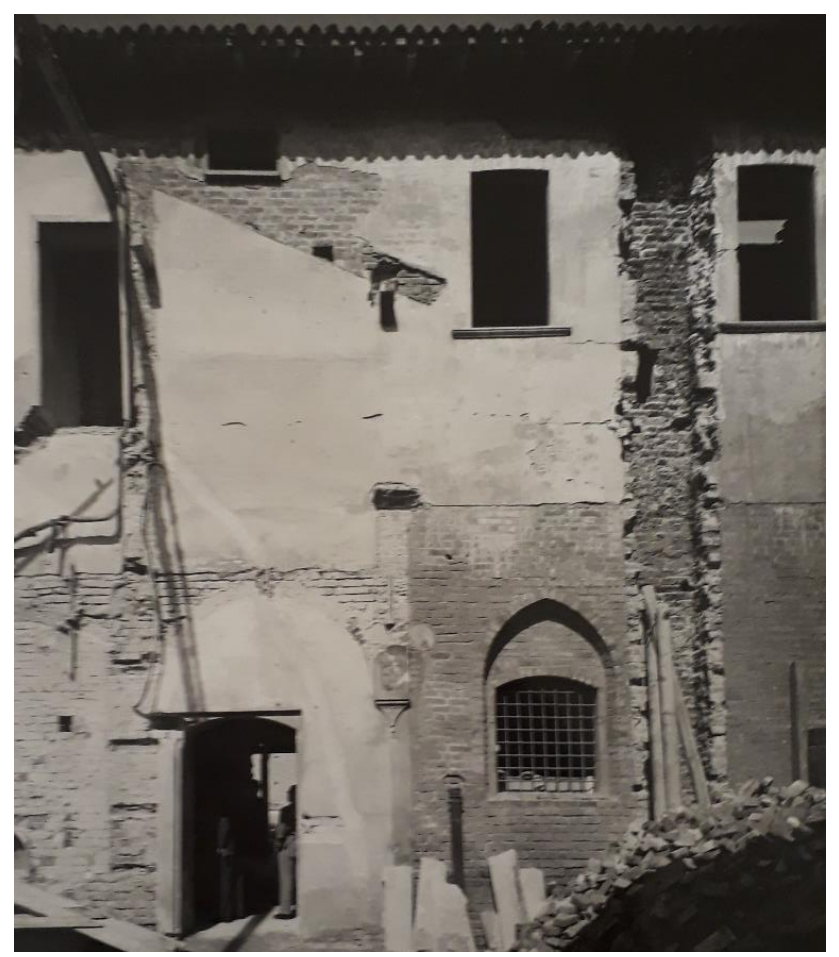

Figure 2. Space between the New Sacristy and the Cloister of the Prior, demolished after II World War to enlarge the New Sacristy and renew the layout of the complex. 
Another place deeply analysed during this research is the Small Sacristy; in a similar way as the New Sacristy, it could be considered as a resultant space created to fill the gap between the transept and the Cloister of the Frogs, considering that writings and decorations on its walls bring us back to the age of construction of the Bramante's Cloister.

The historic stratifications and the evolution of these places over the years have been particularly peculiar and interesting. This is one of the reasons why it was decided to deeply study these environments through an accurate digital survey and the creation of an interactive virtual simulation. In this way, most of the tales linked to the history of the convent can be clarified and directly experienced (such as the attempt of Ludovico il Moro to modernize the convent according to the dictates of the Renaissance).

\section{DIGITAL SURVEY AND 3D MODELLING}

\subsection{Combined digital survey}

The present experimentation started from an in-depth digital survey, that allowed to acquire the geometric and chromatic data with a high level of accuracy. With a view to obtaining this precision, it was decided to take into consideration both active and passive surveying tools, using, during the survey campaigns, two different terrestrial laser scanners and a Canon EOS 70D camera for sfm (structure from motion) photogrammetry. The combination of these three instruments depended on the contingent needs and characteristics of the analysed environments.

Because of the complexity of the surveyed object (as regards morphology and colours), the laser scanners have been used to acquire all the architectural envelops, paying a particular attention to some specific elements (such as the white walls of the two cloisters and the vaults of the Cloister of the Frogs, which have very few discontinuities and are devoid of significant reference points, so it is difficult to survey them with other tools); photogrammetry, instead, has been chosen as reference to reconstruct the most complex chromatic data.

The research group surveyed the entire complex through two survey campaigns, conducted in two different moments. During the first survey campaign, only the Cloister of the Frogs was acquired with a phase-based Leica HDS 7000 laser scanner without external camera. This instrument is characterized by an acquisition speed of more than 1 million point per second and a linear error less than $1 \mathrm{~mm}$. The laser acquisition range is from $0.3 \mathrm{~m}$ to $187 \mathrm{~m}$, with an average accuracy of $0.5 \mathrm{~mm}$ when the scan is less than $10 \mathrm{~m}$ from the surveyed object. The scanning resolution was set at $6 \mathrm{~mm}$ at a distance of $10 \mathrm{~m}$.

In order to entirely survey the cloister, 8 scans from the portico and 8 scans from the garden were recorded. In particular, the 8 scans in the garden were organized in such a way as to acquire the internal perimeter of the cloister, bypassing the obstacles represented by the trees (Fig. 3).

Contextually, a photographic dataset of the coloured parts of the cloister (such as the fountain, the columns, the arches, the basreliefs and the epigraphs on the walls) was captured with the Canon camera.

The same acquisition procedure (laser scanner associated with camera) was used during the second survey campaign. In this case, the research team acquired 25 scans using a time-of-flight Leica P30 laser scanner, characterized by an extremely rapid scanning speed (equal to 1 million points per second) and a range that goes from a minimum of $0.4 \mathrm{~m}$ to a maximum of 120 $\mathrm{m}$. Unlike the Leica HDS 7000, this laser is equipped with an integrated camera that allows to take HDR images (4 megapixels for each image $17^{\circ} \mathrm{x} 17^{\circ}, 700$ megapixels for panoramas) useful for texture reconstruction (nevertheless, as will be seen, the laser scanner's camera was used only in the Old Sacristy).

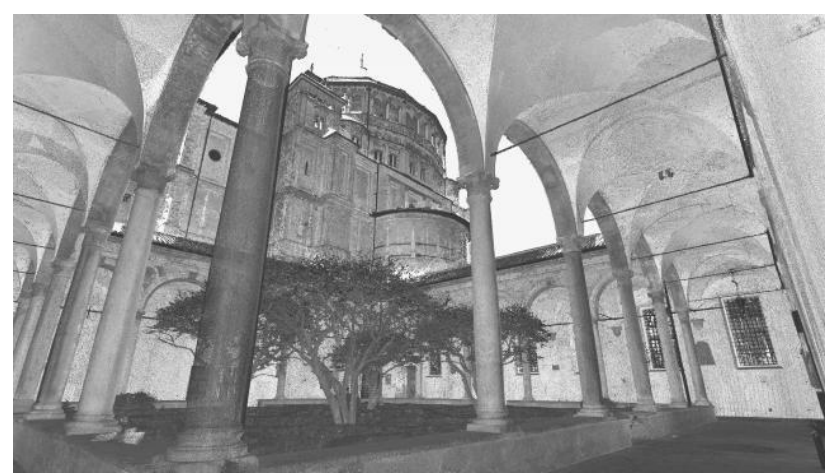

Figure 3. Point cloud of the Cloister of the Frogs, acquired by the Leica HDS 7000 laser scanner.

With these tools, all the other analysed environments (Small Sacristy, New Sacristy, Old Sacristy, Cloister of the Prior) were acquired.

Considering its dimensions, the Small Sacristy required only 3 laser scans. At the same time, a consistent photographic dataset was taken in order to acquire all the details of the rich decorative apparatus of the walls.

Instead, 5 scans were recorded in the New Sacristy. 3 of them were aimed at acquiring the northern apse of the church, that delimits one of the sides of the room. The number of scans (relatively few with respect to the great dimensions of the environment) and their placement are due to the features of the sacristy: unlike the other surveyed spaces, it was built in recent times and, for this reason, it is mostly characterized by simple surfaces without any significant decorative elements, that do not require the acquisition of a large amount of data. This is why only the Renaissance apse (that is the only considerable architectural element in this environment) was captured with the camera.

In order to survey the Old Sacristy, 11 scans were acquired: 8 along the two longer sides ( 4 on the left and 4 on the right), taken at a height of about $170 \mathrm{~cm}$ from the floor, 1 in the apse (taken at $170 \mathrm{~cm}$ in height as well), and 2 in the central part of the nave, at a height of about $250 \mathrm{~cm}$ from the floor (this different height is due to the need to reduce the hidden areas on the wooden furniture and to better acquire the vault). The first 9 scans were recorded with a resolution of $3.1 \mathrm{~mm}$ at $10 \mathrm{~m}$, the 2 scans in the middle of the nave with a resolution of $1.6 \mathrm{~mm}$ at $10 \mathrm{~m}$. In this case, it was decided to activate the laser scanner's camera, considering that the decorative apparatus of the Old Sacristy is undoubtedly the most complex and valuable, and also the most difficult to survey through photogrammetry (because of the great dimensions and the remarkable height of the sacristy). The scanner took several photos in full dome mode HDR with a resolution of $1920 \times 1920$ pixels for a single frame (Fig. 4). At the end, a photographic dataset was taken in order to acquire all the decorated surfaces (the vault, the apse, the wooden furniture).

Finally, in the Cloister of the Prior, 6 scans were recorded with the Leica P30 laser scanner, while the photographic dataset was acquired by testing two types of lenses, that were applied to the Canon EOS 70D camera: a $18 \mathrm{~mm}$ traditional lens and a fisheye lens. This experimentation is due to the peculiarities of the cloister that make it difficult to obtain the photogrammetric 
data, such as: the small dimensions, the orientation, that causes the lack of a good natural lighting (and an excessive contrast in the photos), and the white walls, which have no significant reference points (imperfections, chromatic variations, etc.) essential for the alignment of the photos during the data processing. Specifically, the fisheye lens proved to have significant strengths and weaknesses: for example, the wide field of view of the fisheye allowed to acquire the little space of the cloister with a small number of images if compared to the photos taken in the same conditions with the traditional lens. An inconvenience of the fisheye is instead related to the quality of the images, which decreases radially (along their edges, the photos taken with this lens show a considerable blurring). This problem can also be accentuated because the photogrammetric software used (Agisoft Metashape) during the texturing phase tries to correct the fisheye distortions producing further alterations. The comparison between the 2 lenses, deeply analysed in a previous research (Bolognesi et al., 2019), led to the final decision to use only the traditional lens (that is able to take photos with a higher and more uniform quality than the fisheye images) in order to acquire the most interesting architectural elements, such as the columns and the brick wall.

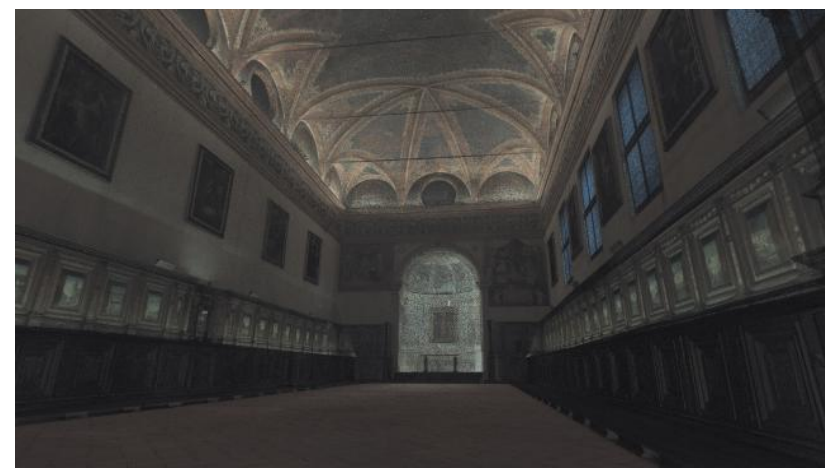

Figure 4. Point cloud of the Old Sacristy, acquired by the Leica P30 laser scanner with activated camera.

\subsection{Data processing and creation of the 3D model}

During the data processing, the laser scans recorded in situ have been aligned each other in Cyclone, obtaining a single point cloud. The latter was then imported into Autodesk Recap Pro, where it was cleaned up and divided into chunks in order to facilitate the subsequent phases, during which the textured meshes were created and used to reconstruct the 3D models of all the studied environments.

Each 3D model is constituted partly by NURBS surfaces, partly by textured meshes. The presence of these two categories of objects depends on the heterogeneous characteristics of the surveyed elements.

In some cases, in fact, it was decided to convert the laser scanner point clouds into meshes using CloudCompare; these meshes were then imported into Rhinoceros where it was possible to trace their profiles and to reverse model all the simplest architectural elements in the form of NURBS with a high accuracy level. These elements were then exported as lighter meshes and texturized using the material library of the VR engine or applying photo-straightened images (such as in the case of the canvases in the New Sacristy). This procedure contributed to guarantee a fluid and optimized VR experience, since the heavy meshes were reduced to the strictly necessary ones.

Instead, in the case of complex architectural objects characterized by a significant chromatic component, the meshes have been directly included in the $3 \mathrm{D}$ models. In this case, the research focused on the attempt to associate a good chromatic information with these meshes.

To achieve this goal, two automated workflows have been used. They are characterized by two different ways to combine the geometric information contained in the laser scanner point cloud with the photogrammetric data.

The first procedure was aimed at creating the textured meshes included in the 3D models of the two cloisters, of the Small Sacristy and of the apse of the New Sacristy. In these cases, once the photographic dataset of the architectural element was collected, it was imported and aligned within Agisoft Metashape, obtaining a photogrammetric mesh. The latter was georeferenced with respect to the laser scanner data using markers (not less than 4 to guarantee a good alignment). Subsequently, the laser scanner mesh of the same element (created on CloudCompare) was imported into Metashape, replacing the photogrammetric one (Fig. 5). Finally, the texture was built on the basis of the photogrammetric data and applied to the laser scanner mesh.

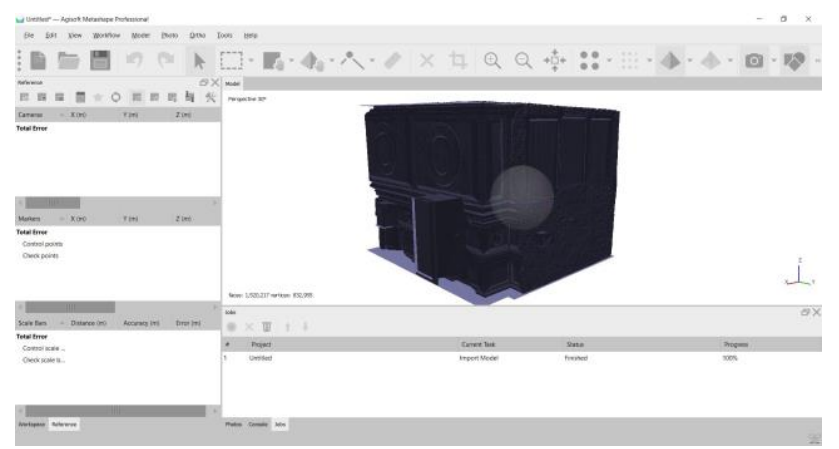

Figure 5. Mesh of the Small Sacristy, obtained from the laser scans and imported into Agisoft Metashape.

This process made it possible to create meshes with a high level of detail and with a good texture quality: in summary, every mesh was built using the laser scanner data (that allow a good acquisition of the geometry), while the corresponding texture was obtained from the photogrammetric dataset (that allows a better acquisition of colours) and was then projected on the laser scanner mesh.

The second procedure was used, instead, to create the textured meshes of the Old Sacristy. As mentioned, it was the only environment acquired by using the laser scanner with the activated camera. Nevertheless, considering that the lighting conditions did not allow a perfect acquisition of the photographic dataset, the quality of the photos captured with the laser scanner was not high. For this reason, before exporting the point cloud, it was necessary to modify the panoramic photos within a photo-editing software (in order to improve the quality of the less readable areas of the images) and to re-import them into Cyclone. The point cloud created after this procedure was then exported in e 57 format. In order to create the mesh from such a heavy file (an e57 weighs about $60 \mathrm{~Gb}$ ), the potential of two software, Agisoft Metashape and RealityCapture, was analysed. Specifically, it was decided to carry out a test importing the entire point cloud into both software and processing a portion of it (the vault of the sacristy). The results obtained were then noted, bringing out pros and cons.

This analysis showed that some significant strengths of RealityCapture are related to:

- the import speed (only a few minutes in this software, several hours in Metashape); 
- the possibility of aligning together the photogrammetric and laser scanner data: for each station, the software recognizes the photographic images that have been recorded by the laser scanner's camera. Therefore, the software is able to orient the photogrammetric data according to the laser data (that is more accurate);

- $\quad$ the possibility of creating meshes with an extremely high number of faces even when the RAM is not able to display them: when it happens, the software builds the mesh in any case but displays it in a simplified way (in the form of a set of points). Therefore, the object can be easily managed and less strains the RAM.

On the basis of this test, the most complex and peculiar parts (vault, apse, wooden furniture) of the Old Sacristy were reconstructed in the form of textured meshes within RealityCapture (Fig. 6).

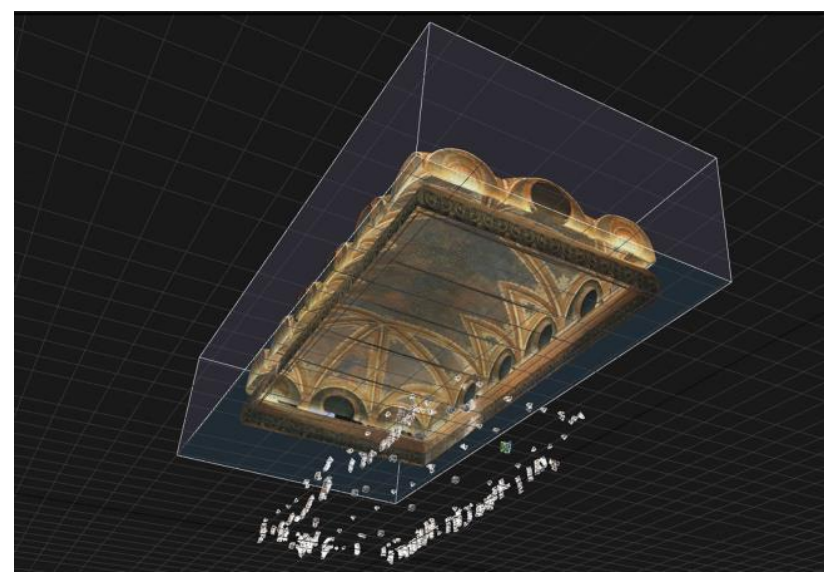

Figure 6. Textured mesh of the vault reconstructed using both laser scanner and photogrammetric data within RealityCapture.

In the following lines, all the 3D models obtained from these workflows are listed and described in detail, with particular reference to the elements modelled on Rhinoceros as NURBS and to the elements reconstructed in the form of textured meshes:

- The Cloister of the Frogs' model was created by modelling as NURBS the vaults, the walls, the doors, the windows, the flowerbeds, the fountain, while the arches, the columns, the epigraphs, the bas-reliefs were reconstructed in the form of textured meshes (Fig. 7).

- The Cloister of the Prior's model was created by modelling as NURBS the white walls, the doors, the windows, the mouldings, the roof, while the columns, the corner pillars, the floor and the brick wall were reconstructed in the form of textured meshes.

- The Old Sacristy's model was created by modelling as NURBS the walls, the floor, the doors, the windows, the picture frames, while the vault, the apse, the wooden furniture were reconstructed in the form of textured meshes.

- Almost the entire New Sacristy was modelled in the form of NURBS, except for the northern apse of the church. This choice is due to the characteristics of this room, built after World War II, that does not present a high artistic instance or a particularly valuable decorative apparatus (except for the Renaissance Bramante's apse).

- Almost the entire Small Sacristy was reconstructed as a textured mesh, except for the floor and the ceiling. This choice is linked to the extremely small size of the sacristy (which made the survey relatively easy and allowed to build a not particularly heavy mesh) and to its elaborate and extensive decorative apparatus, which could not be reproduced with precision through the reverse modelling.

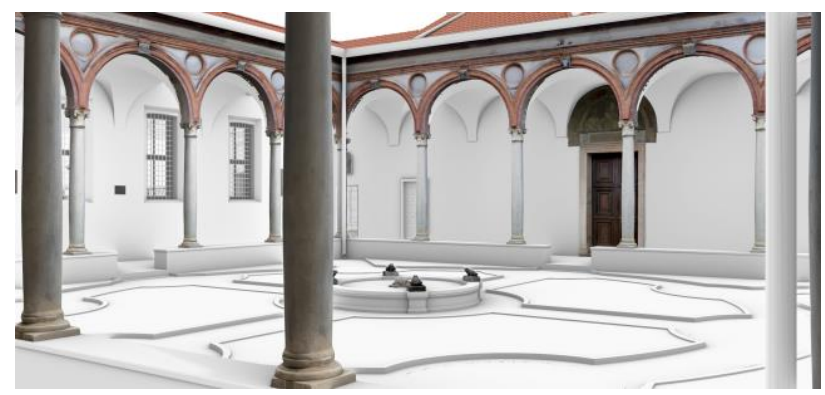

Figure 7. Complete 3D model of the Cloister of the Frogs. The coloured elements are the ones obtained in the form of textured meshes, the white elements are the ones modelled on Rhinoceros as NURBS.

As a final step of the models' reconstruction, after being retopologized (process described in the following paragraph), all the textured meshes were unified with the NURBS geometries in one 3D model of all the surveyed environments (Fig. 8).

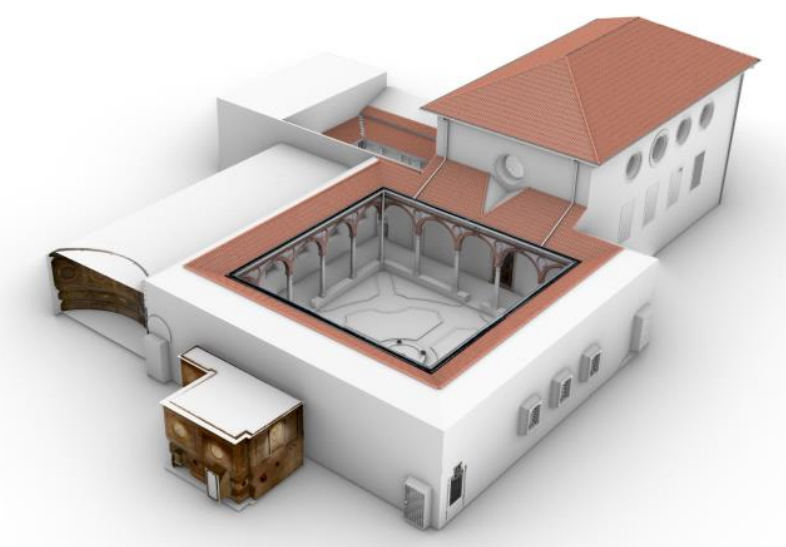

Figure 8. Complete 3D model displayed on Rhinoceros. The coloured elements are the ones obtained in the form of textured meshes, the white elements are the ones modelled on Rhinoceros as NURBS.

\subsection{Retopology of the 3D meshes}

The meshes created through laser scanning and photogrammetric techniques are difficult to manage, considering their complexity and the high count of faces they are made of, and they need to be optimized. For this reason, they were imported into ZBrush, a software that allows to retopologize meshes. Retopology consists in optimizing the number of polygonal faces and changing their triangular geometry in a quadrangular one, more easily manageable. In order to reach this goal, the mesh is duplicated. One of the two clones is the reference model from which the detail information is acquired; the other one is the model that will be subjected to retopology. Once the cloned model has been retopologized, the detail level of the reference model will be projected on the second one (Palestini et al., 2017; Aiello et al., 2019). After this phase, an UV map is created: it allows to correctly apply a 2D texture on the 3D model. To achieve this goal, the mesh is first unwrapped on a plane, acquiring two coordinates for each vertex ( $\mathrm{X}$ and $\mathrm{Y})$. The image chosen as a texture is then 
overlapped on this plane, acquiring two coordinates (called UV coordinates) comparable to $\mathrm{X}$ and $\mathrm{Y}$. Through the UV coordinates the image can be correctly applied to the faces of the 3D model (Fig. 9).
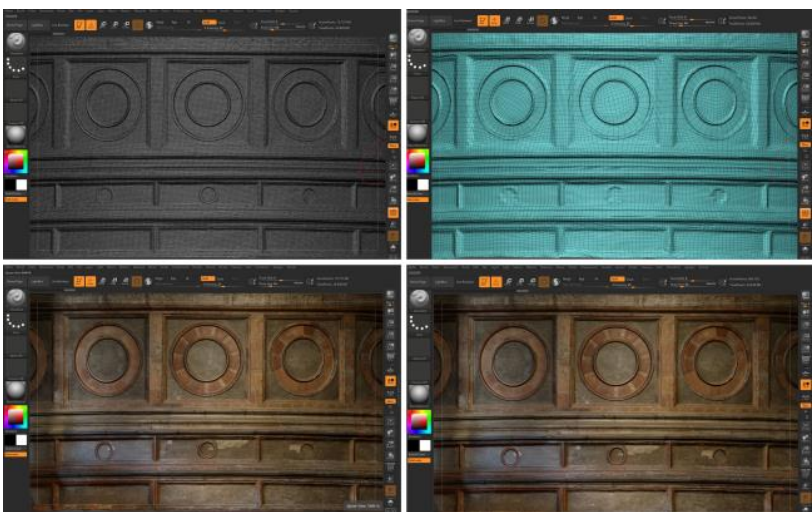

Figure 9. Workflow for the retopology of the mesh. On the left, the triangular mesh; on the right, the retopologized mesh. The apparent level of detail between the two meshes is the same.

\section{VIRTUAL REALITY EXPERIENCE}

\subsection{Game Engine}

As mentioned, the ultimate goal of this experimentation was to use the 3D model of the two cloisters and the three sacristies to create an interactive virtual reality experience, able to allow an in-depth exploration of the surveyed environments and thus promote their knowledge and enhancement. The tool used to create the VR simulation is Unreal Engine. This game engine was chosen for its relatively intuitive use mode, based on the Blueprint Visual Scripting system. This type of scripting system is characterized by a node-based interface that replaces the complex $\mathrm{C}++$ programming language. Thanks to this system, every operation within the game engine can be carried out by simply connecting nodes, without writing any codes as in traditional programming. Actually, connecting blueprint nodes to perform any operation (such as making interactions, creating a material, building lights) is equivalent to using in an implicit way the programming language, as every blueprint nodes contains a script. Thanks to its accessibility, the Blueprint system is extremely effective and gives designers the possibility of using tools generally available only to programmers.

\subsection{VR headset}

The VR simulation of Santa Maria delle Grazie was designed to be performed with an Oculus Rift device, developed by Oculus VR. It is a wearable headset capable of letting the users experience a virtual environment. The specifications of the Oculus Rift are:

- Head-mounted display

- OLED display technology

- $2160 \times 1200$ resolution $(1800 \times 1200$ per eye $)$

- $\quad 90 \mathrm{~Hz}$ refresh rate

- 110 degrees or greater field of view (nominal)

- Compatible with Microsoft Windows (plans for OS X and Linux compatibility)

The Oculus Rift comprises an integrated audio VR, thus providing a 3-D audio effect. It also includes rotational and positional tracking accomplished with the help of infrared LEDs which are detected by a separate IR camera. Therefore, it can be used while users are sitting, standing or walking around the room.

\subsection{VR simulation}

After exporting the model of the complex in obj, it was imported within Unreal Engine for the creation of the VR simulation (Fig. 10).

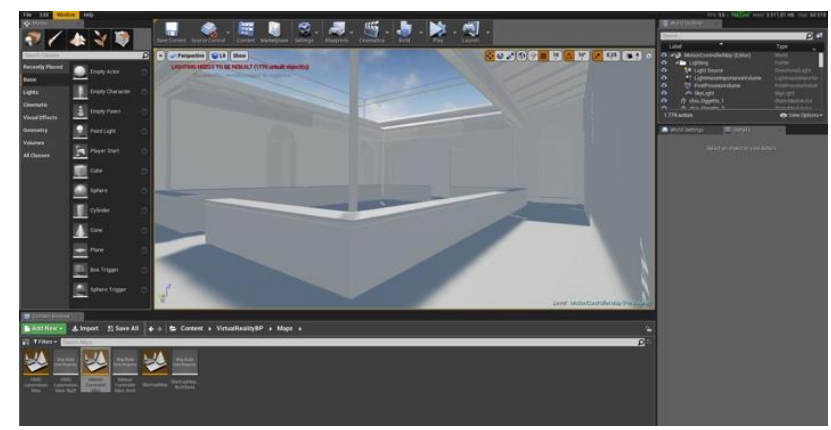

Figure 10. 3D model of the Cloister of the Prior imported within Unreal Engine.

While designing the VR experience, particular attention has been paid to all the expedients (the materials, the type of lighting, the construction of an engaging storytelling) able to guarantee an adequate level of immersiveness and interactivity. Specifically, as regards the system of locomotion, a free movement mode through teleportation has been set up to allow the user movements within the model: this means that it is possible to teleport to any desired location after pointing it with the controllers.

The visit starts from the Cloister of the Frogs, the ideal fulcrum of the complex, around which the other environments are placed (Fig. 11).

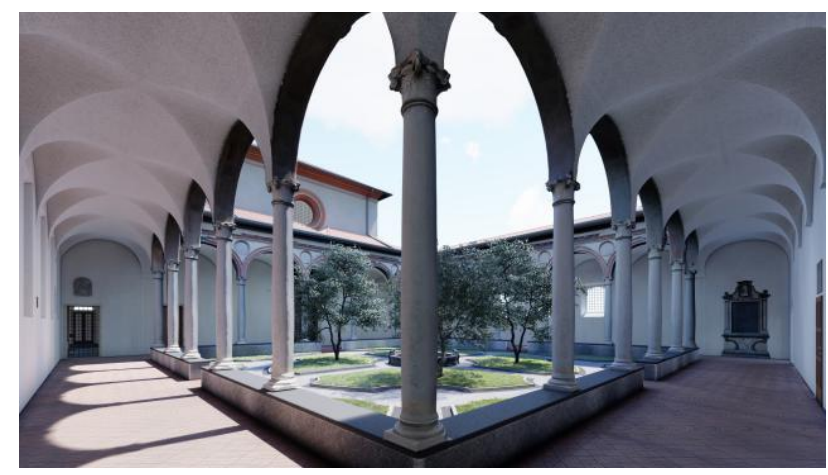

Figure 11. VR experience: The Cloister of the Frogs.

From here, the user can freely move through the three sacristies and the Cloister of the Prior simply by teleporting and by opening all the doors with his own virtual hands. Along the way, some bright spots and audio contents will signal to the visitor the valuable elements of the location that he is standing in: the Cloister of the Frogs, with its Renaissance arches and the picturesque fountain that gives the name to the place; the Small Sacristy (Fig. 12), with its precious sixteenth-century decorative apparatus that hides the traces of the Virgin's face, perhaps sketched by Leonardo da Vinci; the New Sacristy, bordered by the northern transept of the church (Fig. 13); the small Cloister of the Prior, with its Ionic columns and the evocative Latin inscription on the entablature (Fig. 14); and finally the Old 
Sacristy, with its splendid decorative apparatus and the ancient wooden cabinets.

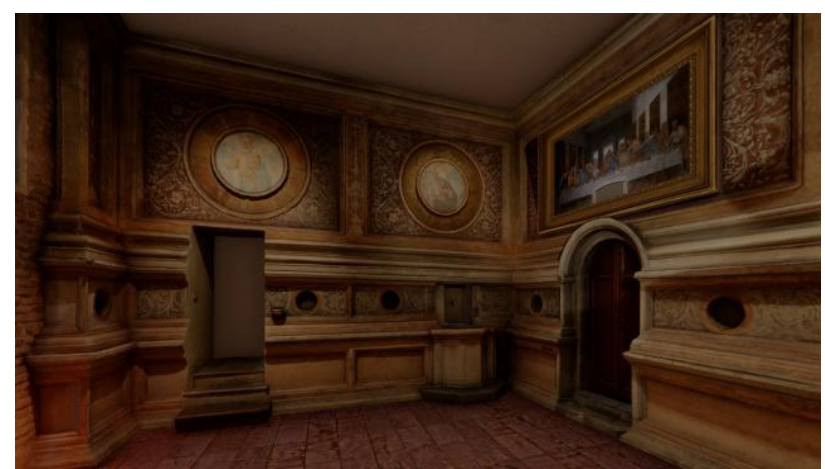

Figure 12. VR experience: The Small Sacristy.

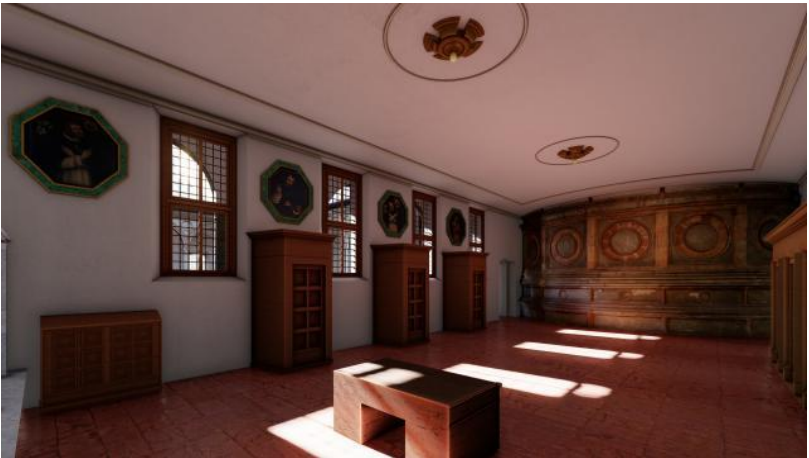

Figure 13. VR experience: The New Sacristy.

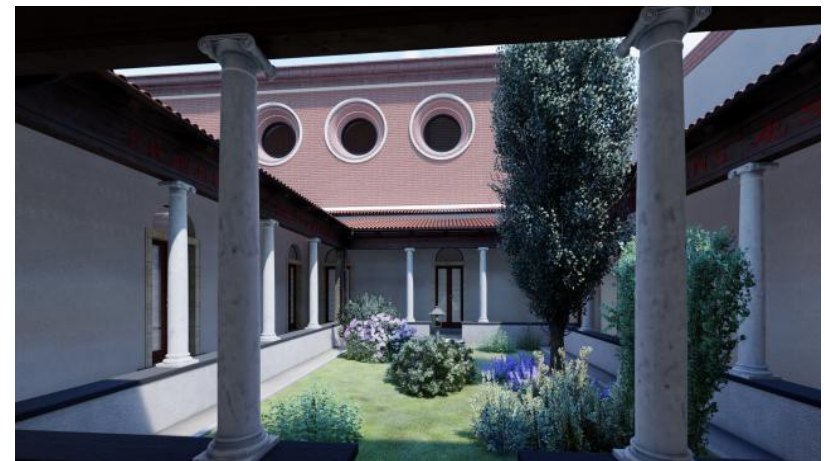

Figure 14. VR experience: The Cloister of the Prior.

In general, there are several simple interactive elements, such as the doors, which can be opened manually, or the info-points, that appear (as the user approaches) in the form of textual panels or multimedia contents (images, audio and videos) and that tell the history of the convent and the events related to the great protagonists who gave life to this masterpiece of GothicRenaissance architecture.

\section{CONCLUSION AND FUTURE RESEARCH}

The present research focused on the creation of a VR immersive and interactive simulation that makes it possible to experience a part of the convent of Santa Maria delle Grazie in Milan, one of the most emblematic Gothic - Renaissance architectures in the historic centre of the city. It hosts iconic art masterpieces just as Leonardo da Vinci's Last Supper and the Tribune, probably designed by Donato Bramante.

This complex has gone through an extremely troubled history: it is the result of remarkable stratifications that had their culmination at the end of the fifteenth century (when the church and convent, designed by Guiniforte Solari, were radically modified and enlarged at the behest of Ludovico il Moro) and during the 20th century (when the convent was bombed during the war events of 1943).

This experimentation found an effective support in the digital survey techniques, the 3D modelling and the use of virtual reality, conceived as tools to raise awareness of the heterogeneous characteristics and the extraordinary beauty of this case study.

The choice of the immersive and interactive VR simulation takes its origin from a profound awareness: that virtual reality, with its (potentially) infinite possibilities, is perhaps the most effective means to explore places far away from us in space and time, to evaluate their geometry and morphology, and to know their secrets in ways otherwise unthinkable. This technology thus gives the user the unrepeatable possibility of experiencing places that are difficult to access or historical and artistic sites that time has damaged or destroyed, preventing them from being forgotten. The virtual reality / cultural heritage binomial also allows to associate the experimentation with an emotional approach, since VR appeals not only to the rational part of the user, but also (and above all) to the emotional one.

The virtual simulation was developed, in this case, starting from a detailed digital survey (conducted with different methodologies) of some of the most significant and at the same time less known parts of the complex (the Old Sacristy, the Small Sacristy, the New Sacristy, the Cloister of the Frogs, the Cloister of the Prior), which can thus be explored and fully understood by all categories of users, arousing in them a strong emotional involvement during the virtual visit.

In the near future, the research will be focused on the acquisition of other less known parts of the complex affected by the bombing of 1943, such as the Cloister of the Dead and the Great Cloister (both partially reconstructed, altering their original appearance).

Another future purpose of this experimentation is the 3D modelling of the entire complex in its ancient configuration (i.e. before the damages due to the bombing and the reconstruction in the post-war period), on the basis of the old documents found during the archive research.

The ultimate goal of the project is to create a new and more complete VR experience of the monumental complex in its original aspect, using an innovative and captivating storytelling and following the Serious Game paradigm. This simulation will allow new experiences, such as accompanying Bramante on the construction site of the Cloister of the Frogs, witnessing the phases of reconstruction of the convent, listening to revolutionary ideas directly from the voice of Ludovico il Moro, painting the Last Supper next to Leonardo da Vinci. This can be a possible, effective tool to propose innovative forms of learning, immediate and even emotional.

\section{ACKNOWLEDGEMENTS}

We would especially like to thank Brother Adriano Cavallo of the Dominican Order for allowing the free access to the complex of Santa Maria delle Grazie and for accompanying and supporting the researchers with his knowledge during the surveying and modelling phases. In addition, we would also like to thank Brother Guido Bendinelli, the Prior of the convent, for giving us the opportunity to study the ancient documents and projects kept in the archives of the Milan Superintendence. 


\section{REFERENCES}

Aiello, D., Basso, A., Spena, M. T., D'Agostino, G., Montedoro, U., Galizia, M., Grasso, R., and Santagati, C., 2019. The Virtual Batcave: a project for the safeguard of a Unesco WHL fragile ecosystem. In: Int. Arch. Photogramm. Remote Sens. Spatial Inf. Sci., Vol. XLII-2/W9, pp. 17-24, doi.org/10.5194/isprs-archives-XLII-2-W9-17-2019.

Bolognesi, C. and Aiello, D., 2019. Forgotten Architecture: smart tools for cultural tourism in the Cloister of the Prior (Santa Maria delle Grazie, Milan). In: Int. Arch. Photogramm. Remote Sens. Spatial Inf. Sci., Vol. XLII-2/W11, pp. 247-253, doi.org/10.5194/isprs-archives-XLII-2-W11-247-2019, 2019.

Anderson, E., McLoughlin, L., Liarokapis, Peters, F., C., Petridis, P., and De Freitas, S., 2010. Developing Serious Games for Cultural Heritage: A State-of-the-Art Review. Virtual Reality, 14(4).

ArtGlass, 2017. Bergamo: Viaggi d'acqua. https://www.artglass.it/progetti/.

Banfi, F., Brumana, R., and Stanga, C., 2019. A content-based immersive experience of Basilica of Sant'Ambrogio in Milan: from 3D survey to virtual reality. In: Int. Arch. Photogramm. Remote Sens. Spatial Inf. Sci., Vol. XLII-2/W11, pp. 159-166, doi.org/10.5194/isprs-archives-XLII-2-W11-159-2019.

Bevilacqua, M. G., Caroti, G., Piemonte, A., and Ulivieri, D., 2019. Reconstruction of lost architectural volumes by integration of photogrammetry from archive imagery with 3-D models of the status quo. In: Int. Arch. Photogramm. Remote Sens. Spatial Inf. Sci., Vol: XLII-2/W9, pp. 119-125, doi.org/10.5194/isprs-archives-XLII-2-W9-119-2019.

Campi, M., di Luggo, A., Palomba, D., and Palomba, R., 2019. Digital surveys and 3D reconstructions for augmented accessibility of archaeological heritage. In: Int. Arch. Photogramm. Remote Sens. Spatial Inf. Sci., Vol. XLII-2/W9, pp. 205-212, https://doi.org/10.5194/isprs-archives-XLII-2-W9205-2019.

Candy, L., Ferguson, S. (Eds.), 2014. Interactive Experience in the Digital Age. Springer, New York.

Carrión-Ruiz, B., Blanco-Pons, S., Duong, M., Chartrand, J., Li, M., Prochnau, K., Fai, S., and Lerma, J. L., 2019. Augmented experience to disseminate cultural heritage: House of Commons windows, Parliament Hill National Historic Site (Canada). In: Int. Arch. Photogramm. Remote Sens. Spatial Inf. Sci., Vol. XLII-2/W9, pp. 243-247, https://doi.org/10.5194/isprs-archives-XLII-2-W9-243-2019.

Curiosity Stream, Experius Vr, Reality Virtual, 2018. Nefertari: Journey to Eternity.

https://www.oculus.com/experiences/rift/1491802884282318/.

Dhanda, A., Reina Ortiz, M., Weigert, A., Paladini, A., Min, A., Gyi, M., Su, S., Fai, S., and Santana Quintero, M., 2019. Recreating Cultural Heritage environments for VR using photogrammetry. In: Int. Arch. Photogramm. Remote Sens. Spatial Inf. Sci., Vol. XLII-2/W9, pp. 305-310, https://doi.org/10.5194/isprs-archives-XLII-2-W9-305-2019.
Gaitatzes, A., Christopoulos, D., and Roussou, M., 2001. Reviving the past: cultural heritage meets virtual reality. In: Proceedings of the 2001 conference on Virtual reality, archaeology, and cultural heritage, pp. 103-110, ACM.

Liestøl, G., 2014. Along the Appian Way. Storytelling and Memory across Time and Space in Mobile Augmented Reality. In: EuroMed 2014, LNCS 8740, pp. 248-257.

Mandelli, A., Achille, C., Tommasi, C., and Fassi, F., 2017. Integration of $3 \mathrm{D}$ models and diagnostic analyses through a conservation-oriented information system, in Architecture, Built environment and Construction engineering (A.B.C.). In: The International Archives of the Photogrammetry, Remote Sensing and Spatial Information Sciences, Vol. XLII-2/W5, 2017, 26th International CIPA Symposium 2017, 28 August - 01 September 2017, Ottawa, Canada.

Martelli, G., 1981. Il refettorio di Santa Maria delle Grazie in Milano e il restauro di Luca Beltrami nell'ultimo decennio dell'Ottocento. Istituto Poligrafico e Zecca dello Stato, Roma.

Palestini, C., Basso, A., 2017. The photogrammetric survey methodologies applied to low cost 3D virtual exploration in multidisciplinary field. In: Int. Arch. Photogramm. Remote Sens. Spatial Inf. Sci., Vol. XLII-2/W8, pp. 195-202.

Palma, V., Spallone, R., and Vitali, M., 2019. Augmented Turin baroque atria: AR experiences for enhancing cultural heritage. In: Int. Arch. Photogramm. Remote Sens. Spatial Inf. Sci., XLII2/W9, pp. 557-564, doi.org/10.5194/isprs-archives-XLII-2-W9$557-2019$.

Pietroni, E., 2013. Natural interaction in VR environments for cultural heritage: the virtual reconstruction of the RegoliniGalassi tomb in Cerveteri. Archeologia e Calcolatori, 24, pp. 231-247.

7reasons Medien GmbH, 2018. Carnuntum app. https://www.carnuntum.at/en/visitor-information/carnuntumapp.

Tommasi, C., Achille, C., and Fassi, F., 2016. From point cloud to BIM: a modelling challenge in the cultural heritage field. In: The International Archives of the Photogrammetry, Remote Sensing and Spatial Information Sciences, Vol. XLI-B5, XXIII ISPRS Congress, 12-19 July 2016, Prague, Czech Republic. 